\title{
A STUDY ON THE ROLE OF INSTAGRAM IN BUSINESS DEVELOPMENT CYCLE OF NETPRENEURS
}

\section{Ebrahim M K}

\section{Mohammed Midlaj} Kozhukkal*

\author{
Assistant Professor, Dept. of Management Studies Devamatha Arts and \\ Science College, Kannur
}

Assistant Professor, Dept. of Management Studies Manhaj Women's Academy, Kannur ${ }^{*}$ Correspopnding Author

ABSTRACT

Instagram is setting of as a legitimate social media platform for endorsing the products and services online. Nowadays, both large and small business organizations make use of Instagram account to attract new customers as well as to interact with existing customers. Looking at the opportunities gained by business through social media, Instagram: one of the fastest growing social media platform is a crucial part for those people who operate business on the internet. This research paper explores how Netpreneurs utilize Instagram to access and analyse the target audience, deliver information and awareness and maintain customer relationship.

KEYWORDS : Netpreneurs, Instagram, social media marketing, modern trends in business, online business

\section{INTRODUCTION}

Social media has become an integral part of human lives and so many people are being represented on social media, it is ideal for business people to connect with their customers. After the emergence of Facebook and Twitter, Instagram has joined the trend in 2010. Instagram permits business people to share information to their customers through photos, videos and stories and interact with them by comments and instant messaging. As per Instagram's internal report 2018, there are more than 1 billion Instagram accounts worldwide active every single month. As of now Instagram is emerging as one of the favorite social media platform and thereby business peoples' new aged strategic marketing tool. Instagram regularly updates their features and recently added 'Instagram for business' that allows users to generate free business profile and sell their products and services on Instagram. These initiative opened a new door of possibilities for those people who operate business on the internet, i.e. Netpreneur. Now, it is the challenge of Netpreneurs to make visual expressions of their business to inspire visible actions from people around the world. This study makes an effort to identify the role of Instagram on business development cycle of Netpreneurs.

\section{OBJECTIVES}

1. Advantages of Instagram on analyzing and accessing target audience.

2. Advantages of Instagram on delivering information and awareness.

3. Advantages of Instagram on maintaining customer relationship and engagement.

Advantages of Instagram on analyzing and accessing target audience in business development cycle of Netpreneur

The very first and the most important concern of the Netpreneurs in their business development process is defining and analyzing the target audience. This includes being aware of the behavioural habits, motivation, interests and general characteristics shared by individuals who are interested in the product or service that are offered by the Netprenuer. There was a time when accessing and analyzing target audience was a painstaking and time consuming process. Thankfully, the age of digital and social media analytics has made gathering the information needed by the business people more effective and easy. Social media networking sites do not only provide user to expand personal network but also provide a platform for business people to interact with potential customers (Blackman, 2009). Through the use of social media platforms, what would have taken months of work before can be completed in few clicks.

Just like other social media platforms, Instagram also helps to gather information related to target audience with an extra boost because of the 'Instagram for business' and 'co-creative' features. 'Instagram for business' facilitates Netpreneurs to generate strong and attractive profile to access their target customers. Also, Netpreneurs can get real-time matrix on the performance of a posted content. This includes reach, impressions, interactions and profile visits. Through business accounts, Netpreneurs can view the audience insight and see three most fundamental statistics such as age group, sex, and location of their followers. So 'Instagram for business' will give a lift to determine the possible acceptance or rejection of a particular product or service concept at a very limited span of time. It also helps in evaluating a particular content or Netpreneurs business account itself was accessed or not accessed to the real target audience. 'Co-creative' features of Instagram includes hashtags, Instagram influencers, Instagram challenges and giveaways. Using hashtags related to specific target group while posting photos and videos, a Netprenuer can easily access the target audience. Instagram influencers are those Instagram users who have an established credibility and audience; who can persuade others by virtue of their trustworthiness and authenticity. Netpreneurs can coordinate their marketing activities with these influencers or trendsetters in the specific target group will help to increase accessibility to target audience. Challenges and giveaways organized by Netpreneurs through Instagram also contributes to the same. Netpreneurs can post their content that is strongly connected to their target audience will affect the level of user interaction and trust in their target audience. Moreover, Netpreneurs can conduct real-time polls and researches through their stories option in Instagram to understand the behaviour of customers towards a specific content.

Numerous ways can be implemented by Netpreneurs through Instagram to access and analyze their target audience. When they take decisions about target audience using the services of Instagram will obtain a sustainable competitive advantage and generate benefits. In order to speed up the process of businesses development, Netpreneurs must identify the needs and interests of their key audience on Instagram by finding customers who matter most to Netpreneurs using targeting options such as location, demographics, interests, behaviors, custom audience and automatic targeting to adapt the choice based priorities and communicate and deliver products and services to the one who is actually in need of. 
Advantages of Instagram on delivering information and awareness in business development cycle of Netpreneurs

Similar to every business, Netpreneur are responsible for conducting timely and accurate advertising campaigns to make the target audience aware of products and services offered by them. Mostly Netpreneurs prefer to share information and awareness through online platforms because they are operating business on the internet. Nowadays, social media has emerged into popular platform for business people to facilitate fast and effective communication of generated content and extensive sharing of information. As trendsetters in modern business era, most of the Netpreneurs use Instagram, one of the emerging social media platforms to inculcate information and awareness among customers more innovatively.

Companies mainly use Instagram as an evolved marketing channel, in which they can display their products and present further information about their company, in much the same way as in other communication channels. However, Instagram usage differs in some important aspects that are worthy of pointing out (Bergstorm and Blackman,2013) In this era, where everyone is always busy, many customers would prefer looking at visual based advertisement such as pictures and videos than advertisement filled with words. Therefore, the social networking site that best fits the marketing strategy is the Instagram (Lim and Yazdanifard,2014). 'Instagram for business' offers seamless experience for Netpreneurs to drive awareness with highly engaged audience. Apart from Posting content through stories, photos and videos that's also available in other social media platforms, Instagram envisage advertising features namely Carousel Ad, Collection Ad and Ad in Explore. Netpreneurs use Carousel Advertising to present slidable multiple images or videos with multiple description on a single advertisement and clickable link to their webpages. It adds another layer of depth to Netpreneurs advertising contents. Collection Advertising feature on Instagram facilitates Netpreneurs to present swipeable carousel display of images containing full catalogue of their business, and it makes customers to browse, discover and purchase multiple product within the main Instagram feed in a full-screen Canvas called 'Sell products: Grid layout'. 'Ad in explore' helps to reach discovery mindset customers, who are looking to expand their interests beyond the account they follow. Advertisements are automatically loaded to explore tab where Instagram users discover photos and videos related to their specific interests. It is an ideal platform for delivering information and awareness to a user who is not a follower of Netpreneurs' Instagram account. In addition to the above features 'Instagram for business' allows Netpreneurs to track their advertisements through Ad manager. Ad manager is an advertising tool where Netpreneurs can set up and make changes and see the results of all campaigns done through Instagram. If a Netpreneur is short on time for advertising and awareness campaigns, there is an option for them to collaborate with Instagram partners who are proven experts in their field and vetted by Instagram.

As advertising strategy trend moves from the traditional to modern advertising strategies, Netpreneurs use Instagram as a strong tool that differs from other social media platforms in its varied features and direct access to the intended audience. Instagram and its eventual updates best suit Netpreneurs to adopt integrated, attractive marketing communications to build a brand in the minds of customers. Sales promotion massages are often considered as the ugly duckling of marketing: necessary and efficient, but terribly boring. Yet, with Instagram, they might just become the beautiful swan of mobile social media.
Advantages of Instagram on maintaining customer relationship and engagement in business development cycle of Netpreneurs

With the rise of social media and the emergence of smartphones, new possibilities have arisen for Netpreneurs to create and maintain customer relations. Today, customers expect sellers to be represented on social media platforms. Customers today will discuss their opinions about the products and services on social media, regardless of whether the sellers are represented on the platforms or not. Therefore, it is important for Netpreneurs to be present on these platforms in order to be a part of the discussion.

In the case of Instagram, leaving comments and receiving comments on the photo posts can gain more feedback from the customers on the product. Followers are often interested to see the interaction between the organization and the users, so being attentive to the comments would help in improving the relationship with customers (Dennis,2014). Netpreneurs doesn't need face-to-face interaction that can be so important in developing trust and brand loyalty, instead they are concerned with managing the relationships with customers in order to deliver the customer services and value by emphasizing on efficient and effective flows of information online. Instagram allows emergence between two communication partners and allow companies to engage with customers at $a$ lower cost and to a higher efficiency compared to traditional media (Bergstrom and Backman, 2013). Netpreneurs have shifted their view from customers being dependent on business to that of customers as 'equal partners' of the business to share their ideas and viewpoints. It helps to drive customers as an online brand community of the Netpreneur. Creation of brand communities in social media greatly influences brand loyalty and brand trust. Brand communities foster engagement and appeal to the customers need of belongingness, further more building brand communities on social media is good tool to further evolve trust in a brand, this way Netpreneurs can foster the customer engagement through Instagram (Leroche et al,2012). AM Kaplan(2012) developed 'four I's' of social media usage to help firms entertaining this new environment, first- companies should try to integrate their mobile social media activities into the lives of users, second- such integration can be achieved by individualizing activities to take account of each user's preferences and interests, third- involve the user through engaging in conversation, fourth-initiate the creation of usergenerated content and word-of-mouth, which allows for tighter integration of activities into users' lives. Netpreneurs can better install Kaplan's 'four I' model through Instagram because of its varied features which contributes to personalize conversations, deliver quicker response, show customer appreciation through giveaways and contests and easily respond to all the reviews and queries of customers to engage with them in this modern environment.

Netpreneurs can bridge and empower their customers like never before because they manage virtual relationship using Instagram with customers that allows for the creation of revolutionary, new ways of communication. Features of Instagram are extremely important for Netpreneurs in penetrating the number of customers by keeping in touch with them. This can lower the risk of losing customers, improving profitability, and justifying a premium price. Customers of all ages expect that businesses must be represented on social media platforms to find answers for their queries quickly. Instagram make it easy for Netpreneurs to answer the queries, involve customers through conversations and individualize communications for managing customer relationship and engagement. 
CONCLUSION

Sustainable business development for Netpreneurs would be smooth and effective by analyzing and accessing target audience, providing proper information and finally maintaining customer relation in the long run. Proper management of Instagram business accounts will ensure all these are intact. Netpreneurs mainly use Instagram as an evolved marketing channel in which they can display their products and present further information, in much the same way as in other communication channels but Instagram differs in some specific aspects. It is highly convenient for Netpreneurs to access, analyse and attract target audience using Instagram's automated target audience option. Instagram makes Netpreneurs' products and services visually appealing with the help of images, videos and stories, furthermore Instagram for Business is a revolution with Corousel Ad, Collection Ad, Ad in Explore and Ad Manager being its major milestones and thereby helping to reach higher level of interactions and hence creating brand communities. Immediate feedbacks and prompt reply from the business saves time, makes the consumer happy and improves the brand loyalty among the customers. Its major highlight is that it does all this at lower cost and at a higher efficiency. Thus, Netpreneurs can take their business to the next level by utilising Instagram's exclusive business features.

\section{REFERENCES}

1. Varma, M. Dhakane, N. and Pawar, A. (2020). Evaluation of Impact of Instagram on Customer Preferences: The Significance of Online Marketing. International Journal of Scientific and Technology Research, Vol.9, Iss:02, pp.548-554

2. Bergström, T., and Bäckman, L. (2013). Marketing and PR in Social Media: How the utilization of Instagram builds and maintains customer relationships. Retrieved from http:// urn. kb. se/resolve? urn= urn: nbn: se: su: diva-90410

3. Kaplan, A. and Haenlein, M. (2012). If you love something, let it go mobile: Mobile marketing and mobile social media $4 \mathrm{x} 4$. Business Horizons, Vol 55, pp.129-139

4. Lim, SK. and Yazdanifard, R. (2014). How Instagram can be used as a tool in social networking marketing. Retrieved from https://www. researchgate. net/ publication/ 265377226 